\section{Prolonged myoclonus and meningism following propofol}

Niall J. Hughes FFARCSI, James B. Lyons FFARCSI
The purpose of this report is to describe a new complication of propofol administration. A previously fit patient underwent intravenous anaesthesia with propofol for removal of dental wires. Pastoperatively he developed myoclonic jerking of his limbs. On regaining consciousness he complained of an occipital headache, neck stiffness and photophobia, and was found to have nuchal rigidity on examination. These clinical features resolved over the following week. Subsequent investigations failed to explain the aetiology of the symptoms of meningeal irritation, which suggests that propofol was the causative agent. While prolonged myoclonus has been previously described with propofol administration, this is the first report of meningism occurring with its use.

Cette observation décrit une nouvelle complication causée par ladministration de propofol. Un patient jusque là bien portant reçoit une anesthésie intraveineuse pour l'ablation de broches dentaires. Après lintervention, il présente des secousses myocloniques aux membres supérieurs. A la période de réveil, il se plaint de céphalée occipitale, de raideur du cou et de photophobie. A l'examen physique, on note une raideur de la nuque. Ces signes cliniques disparaissent au cours de la semaine suivante. Linvestigation clinique ne parvient pas à expliquer létiologie de ces symptômes dîrritation méningée, ce qui porte d̀ croire que le propofol serait l'agent causal. Alors que des myoclonies prolongées ont déjà été rapportées avec l'administration du propofol, c'est lo première fois que le méningisme est associé à son utilisation.

Key words

ANAESTHESICS, INTRAVENOUS: propofol; COMPLICATIONS: myoclonus, meningism.

From the Department of Anaesthesia and Intensive Care, St. James' Hospital, James' St., Dublin, Ireland

Address correspondence to: Dr. N.J. Hughes Department of Anaesthesia, St. James Hospital, Dublin, Ireland.

Accepted for publication 5th April, 1995.
Propofol was introduced into clinical practice in 1986, and since then has been given to over 16 million patients worldwide (data provided by Zeneca formerly ICI Pharma). The incidence of adverse effects has been low and confined mainly to excitatory neurological manifestations. Increased use, however, has unveiled a broadening spectrum of such phenomena, and here we describe the first case of meningism occurring in association with propofol administration.

\section{Case report}

A 15-yr-old boy, weighing $52 \mathrm{~kg}$, presented for removal of dental wires under general anaesthesia. These had been inserted five weeks previously for fixation of a fractured mandible, and on that occasion anaesthesia $\left(\mathrm{O}_{2}: \mathrm{N}_{2} \mathrm{O}\right.$ : isoflurane following induction with thiopentone) had been uneventful. The patient had no previous medical history, and had not sustained a head injury or loss of consciousness when fracturing his mandible. There was no history of epilepsy, drug abuse or recent infections.

The patient presented as a day case and was unpremedicated. On arrival in theatre intravenous access was established and $50 \mu \mathrm{g}$ of fentanyl were given. Monitoring consisted of non-invasive blood pressure measurement, ECG, and pulse oximetry. After pre-oxygenation, anaesthesia was induced with propofol $175 \mathrm{mg}$, and this was not accompanied by excitatory phenomena or pain on injection. The dental wires were quickly removed (one minute), and no further anaesthetic agents were administered. On resumption of spontaneous ventilation the patient was brought to the recovery room where five minutes after induction of anaesthesia he developed generalised myoclonic jerking. These spasmodic contractions were asynchronous in nature, involved the muscles of his arms, trunk and legs, and were exacerbated by attempts to rouse him. He remained unresponsive and was noted to have a marked disconjugate gaze and pupillary dilatation. This state persisted for $35 \mathrm{~min}$ and during this time temperature, blood pressure, heart rate, arterial blood gas, and blood glucose measurements were within normal limits. Then the patient regained consciousness but there was no improvement in the myoclonus. Diazemuls, $5 \mathrm{mg} i v$, was administered with minimal effect on the myoclonic jerking. 
The patient began to complain of a severe occipital headache which was not effected by posture, and photophobia. On examination he was found to have marked neck stiffness which did not involve the musculature of his shoulder or back, and there was no associated extension of his extremities. A neurological opinion was sought and a CT scan of brain and a lumbar puncture (LP) were performed, both of which were found to be normal. Subsequent cultures and viral studies of CSF fluid were also negative.

Two hours postoperatively the myoclonic movements had decreased in frequency, and the occipital headache, photophobia and neck stiffness had decreased in intensity. The patient was returned to the ward where he was kept for observation. Here his headache which remained unchanged in character, improved slightly in response to nonsteroidal anti-inflammatory agents, and gradually resolved over the next seven days. While the resolution of his neck stiffness followed a similar pattern his photophobia had resolved by the third postoperative day. The myoclonic jerking decreased in frequency but also persisted for one week. At a follow-up visit two weeks postoperatively he was completely asymptomatic.

\section{Discussion}

A wide range of neurological excitatory events ( 37 from 1987-1992) following induction of anaesthesia with propofol has been reported, ${ }^{1}$ including myoclonus, ${ }^{2}$ opisthotonus, ${ }^{3}$ and grand-mal seizures. ${ }^{4}$ In this instance we have described a case of persistent myoclonic jerking associated with symptoms of meningeal irritation following propofol administration.

There can be no doubt that in this case the myoclonus was induced by propofol. Aside from a small dose of fentanyl, propofol was the only drug used. While grandmal seizures have been reported in association with fentanyl, ${ }^{5}$ there have been no reports of dystonic reactions associated with its use. Not only has this phenomenon been well described in association with propofol, but there have also been case reports of these movements persisting for a number of days postoperatively. ${ }^{6.7}$ There is much debate as to whether these neuroexcitatory phenomena, which contradict the convincing evidence of propofol's anticonvulsant activity, ${ }^{8}$ are due to true cortical seizure activity or are due to a subcortical (i.e., midbrain and brainstem) excitatory-inhibitory centre imbalance. ${ }^{9}$ This latter theory is supported by the fact that propofol is thought to have more subcortical potency than other anaesthetic agents, ${ }^{10,11}$ and this effect on subcortical centres may persist at subhypnotic doses.

Associated signs and symptoms of meningeal irritation have not been previously reported with the use of propofol, and it is not easy to explain the possible patho- physiology of the meningeal symptoms in this patient. Their presence in association with a normal CT scan and CSF studies would tend to rule out concurrent infective or neoplastic process. While there are other possible causes for symptoms of meningeal irritation in the presence of normal radiological and CSF studies, their close association with the myoclonus both in intensity and duration would suggest a common aetiological factor. A form of propofol-induced opisthotonus may explain the finding of neck stiffness. This was not, however, associated with any degree of extension of the extremities, nor would it explain fully the patient's headache and photophobia. It is possible that the symptoms of headache and photophobia may have been exacerbated by performing the diagnostic LP. This is not supported by the fact that at no time was the headache related to posture, and that both these symptoms preceded the LP. Meningism has been previously described as part of a central anticholinergic reaction to a scopolamine premedication ${ }^{12}$. As propofol has been shown to have a uniformly depressant effect on the central nervous system it is possible that at subhypnotic doses, inhibition of vagal nuclei may have produced some anticholinergic activity which caused symptoms of meningeal irritation. The marked disconjugate gaze and pupillary dilatation which were present would also suggest abnormal activity at a subcortical level. The accumulating evidence of propofol's specific antiemetic action at subhypnotic doses ${ }^{13}$ indicates a possible action at dopaminergic ${ }^{14}$ and cholinergic sites. Appadu et al. ${ }^{15}$ have recently shown that propofol does not bind strongly to dopamine $D_{2}$ receptors which further supports a possible role for an anticholinergic component to propofol's antiemetic action.

In conclusion it has to be admitted that a conclusive explanation of these neurological manifestations in association with propofol has yet to be found. We can, however, take some comfort in the knowledge that they do appear to resolve completely with time. Ries $e t$ al. ${ }^{16}$ postulated that neuroexcitatory events associated with propofol may have a common mechanism, namely an enduring refractoriness of inhibitory pathways in the brainstem. It may be particularly relevant to this case, that an anticholinesterase agent (physostigmine) proved successful in reversing the opisthotonus in one instance. ${ }^{17}$ In the event of encountering these phenomena, it has been recommended that therapy be aimed at potentiating the inhibitory neurotransmitters glycine and $\ddot{y}$-aminobutyric acid (GABA) using benzodiazepines, physostigmine, and chlormethiazole. ${ }^{16}$

\section{References}

1 Bevan JC. Propofol-related convulsions (Editorial). Can J Anaesth 1993; 40: 805-9. 
2 Reynolds LM, Koh JL. Prolonged spontaneous movement following emergence from propofol/nitrous oxide anesthesia. Anesth Analg 1993; 76: 192-3.

3 Jones GW, Boykett MH, Klok M. Propofol, opisthotonus and epilepsy (Letter). Anaesthesia 1988; 43: 905.

4 Mäkelä JP, Ivanainen M, Pieninkeroinen IP, Waltimo O, Lahdensuu $M$. Seizures associated with propofol anesthesia. Epilepsia 1993; 34: 832-5.

5 Rosenberg $M$, Lisman $S R$. Major seizure after fentanyl administration: two case reports. J Oral Maxillofac Surg 1986; 44: 577-9.

6 Hopkins CS. Recurrent opisthotonus associated with anaesthesia (Letter). Anaesthesia 1988; 43: 904.

7 Gildar $J$. Another case report of opisthotonus and propofol (Letter). Anesth Analg 1993; 76: 1171.

8 Wood PR, Browne GPR, Pugh S. Propofol infusion for the treatment of status epilepticus. Lancet 1988; 1: 480-1.

9 Borgeat A, Wilder-Smith OHG, Suter PM. Propofol and epilepsy: time to clarify! (Letter). Anesth Analg 1994; 78: 198-9.

10 Cavazzuti M, Porro CA, Barbieri A, Galetti A. Brain and spinal cord metabolic activity during propofol anaesthesia. Br J Anaesth 1991; 66: 490-5.

11 Borgeat A, Wilder-Smith OHG, Saiah M, Rifat $K$. Subhypnotic doses of propofol relieve pruritus induced by epidural and intrathecal morphine. Anesthesiology 1992; 76: 510-2.

12 Samuels SI, Washington E. Coma and abnormal neurologic signs following premedication. Anesth Analg 1980; 59: 79-80.

13 Borgeat A, Wilder-Smith OHG, Saiah M, Rifat $K$. Subhypnotic doses of propofol possess direct antiemetic properties. Anesth Analg 1992; 74: 539-41.

14 DiFlorio $T$. Is propofol a dopamine antagonist? (Letter). Anesth Analg 1993; 200-1.

15 Appadu BL, Strange PG, Lambert DG. Does propofol interact with $\mathrm{D}_{2}$ dopamine receptors? Anesth Analg 1994; 79 : $1191-2$.

16 Ries $C R$, Scoates PJ, Puil E. Opisthotonus following propofol: a nonepileptic perspective and treatment strategy. Can J Anaesth 1994; 41: 414-9.

17 Dehring DJ, Gupta B, Peruzzi WT. Postoperative opisthotonus and torticollis after fentanyl, enflurane, and nitrous oxide. Can J Anaesth 1991; 38: 919-25. 